\title{
Correction to: Benthic ostracods (crustacean) as a nearshore pollution bio-monitor: Examples from the Red Sea Coast of Egypt
}

\author{
Ramadan El-Kahawy ${ }^{1} \cdot$ Moataz El-Shafeiy $^{1} \cdot$ Sobhi Helal $^{2} \cdot$ Nabil Aboul-Ela $^{1} \cdot$ M. Abd El-Wahab ${ }^{3}$ \\ Published online: 19 March 2021 \\ (C) Springer-Verlag GmbH Germany, part of Springer Nature 2021
}

Correction to: Environmental Science and Pollution Research (2021) https://doi.org/10.1007/s11356-020-12266-x

1. In section Benthic Ostracods:

1.1. In the 2nd paragraph, (Figs. 7 and 8, and Appendix 2) should be corrected to (Appendix 2-4).

1.2. All repeated (Fig. 9) and (Fig. 10) should be corrected to (Fig. 7) and (Fig. 8), respectively.

2. In section Cluster analysis:

2.1. All repeated (Fig. 11) should be corrected to (Fig. 9).

3. In section Redundancy analysis:

3.1. All repeated (Plate 1) should be corrected to (Fig. $10)$.

4. In section Distribution, diversity indices, and abundances of ostracoda:

4.1. In the 3rd paragraph, (Fig. 9) should be corrected to (Fig. 7).

The online version of the original article can be found at https://doi.org/ 10.1007/s11356-020-12266-x

Moataz El-Shafeiy

motazadel80@cu.edu.eg

1 Geology department, Faculty of Science, Cairo University,

Giza, Egypt

2 Geology Department, Faculty of Science, Fayoum University, Faiyum, Egypt

3 National Institute of Oceanography and Fisheries, Hurghada branch, Hurghada, Egypt
5. In section Ostracod abundance-environmental factors relation:

5.1. In the 2nd paragraph, (Plate 1) should be corrected to (Fig. 10).

6. In section Heavy metal clusters:

6.1. In the 4th paragraph, all repeated (Plate 2) should be corrected to (Fig. 11).

\section{Errors in figures and caption}

Fig. 10 Redundancy analysis (RDA) tri-plot for relative abundance of ostracod species in surface sediment of each station and the associated environmental variables

Fig. 11 Cross-plots compare the relationship between selected ostracod abundances and $\mathrm{Cr}$ content (ppm) for samples from the two sites. $r=$ correlation coefficient

Publisher's note Springer Nature remains neutral with regard to jurisdictional claims in published maps and institutional affiliations. 
Distance

$\begin{array}{lllllllll}675 & 600 & 525 & 450 & 375 & 300 & 225 & 150 & 75\end{array}$

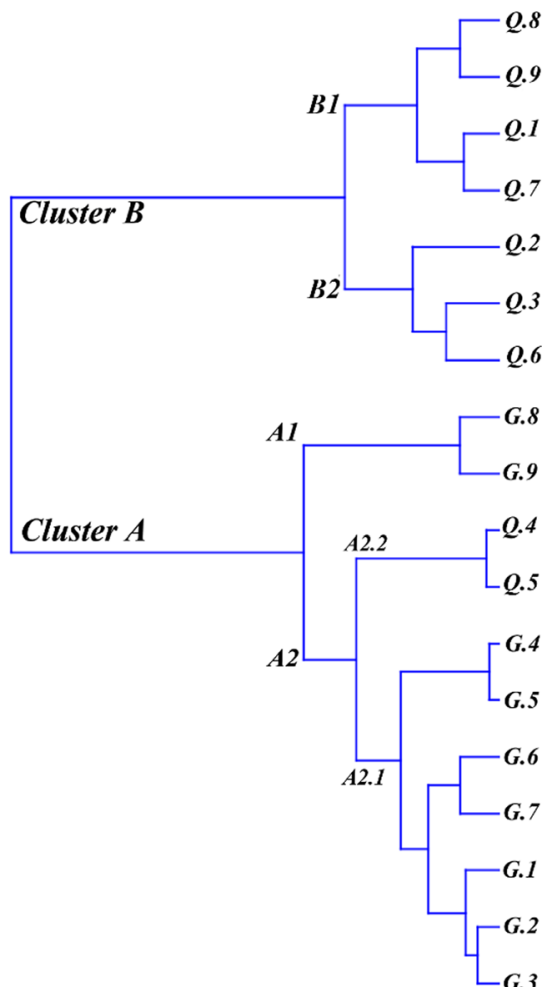

Distance

$\begin{array}{lllllllll}675 & 600 & 525 & 450 & 375 & 300 & 225 & 150 & 75\end{array}$

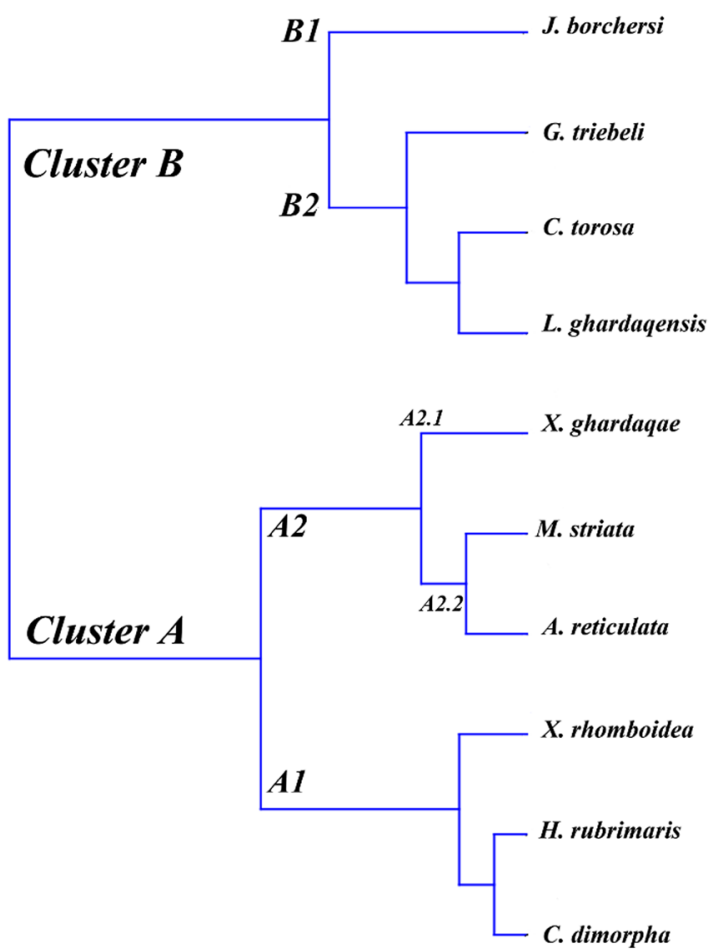

Fig. 9 Q-and R-modes cluster analyses based on the recorded ostracod taxa in 18 variables (samples), using Ward's method for agglomeration 